\title{
Pharmacovigilance study of beta adrenergic receptor antagonists in patients visiting department of medicine of a tertiary care hospital, Surendranagar, Gujarat, India
}

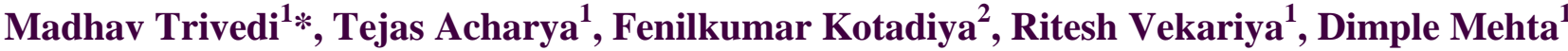

${ }^{1}$ Department of Pharmacology,

C. U. Shah Medical College, Surendranagar, Gujarat, India ${ }^{2}$ Department of Pharmacology, M.P. Shah Medical College, Jamnagar, Gujarat, India

Received: 13 September 2016 Accepted: 08 October 2016

*Correspondence to:

Dr. Madhav Trivedi,

Email: dr.madhav.trivedi@ gmail.com

Copyright: (c) the author(s), publisher and licensee Medip Academy. This is an openaccess article distributed under the terms of the Creative Commons Attribution NonCommercial License, which permits unrestricted noncommercial use, distribution, and reproduction in any medium, provided the original work is properly cited.

\section{ABSTRACT}

Background: The objective of this study was to evaluate incidence, patterns, and severity of Beta blockers induced adverse drug reactions (ADR).

Methods: A total of 500 patients taking Beta blockers were enrolled in the study by taking an informed consent. Reporting of all Beta blockers-induced ADRs was done by filling CDSCO ADR form. All ADR reports were evaluated according to WHO-UMC causality assessment scale.

Results: A total of 64 ADRs (48 males and 18 females) was observed in 500 patients taking beta blockers. Of 64 ADRs, 20 (31.25\%) were mild, 34 $(53.13 \%)$ were moderate, and $10(15.62 \%)$ were classified as severe. 26 $(40.62 \%)$ ADRs were classified as Probable, followed by $22(34.38 \%)$ ADRs were in Possible category, 8 (12.5\%) were in certain category, 4 (6.25\%) ADRs were unlikely and 4(6.25\%) ADRs were Conditional. Among 64 ADRs, 22 $(3.43 \%)$ patients developed bronchospasm, $10(1.56 \%)$ bradycardia, $8(1.25 \%)$ fatigue, $8(1.25 \%)$ nausea/GI upset, $4(0.62 \%)$ erectile dysfunction, $4(0.62 \%)$ dry cough, altered lipid profile, insomnia, night mares and diarrhea are other rare ADRs.

Conclusions: Incidence of ADRs by beta blockers is $12.80 \%$ with bronchospasm as the most common ADR followed by bradycardia. As atenolol is most frequently used beta blocker, ADRs due to atenolol are more common.

Keywords: Beta blockers, Pharmacovigilance, WHO-UMC scale

\section{INTRODUCTION}

Cardiovascular diseases (CVDs) remain a leading cause of morbidity and mortality worldwide. More than $30 \%$ of all the deaths every year are due to CVDs. ${ }^{1}$

Beta-blockers are among the proven medication in Cardiovascular Medicine, reducing both the morbidity as well as the mortality. Currently, beta-blockers are employed in a number of cardiovascular conditions like systolic heart failure, post- myocardial infarction (myocardial protection) and in prevention and treatment of ventricular arrhythmias in post MI patients.

Cardiovascular medications have been cited as one of the most common class of drugs associated with medication errors and ADRs, which need to be monitored from time to time. ${ }^{2}$
Overall, Around $6 \%$ of hospital admissions are estimated to be due to ADRs and about $6-15 \%$ of hospitalized patients experience a serious ADR.

However, sufficient data pertaining to ADRs in Indian population has still not been generated. India rates below $1 \%$ in pharmacovigilance. This is due to ignorance of the subject and also lack of training. ${ }^{4}$

Looking at the scenario of the burden of cardiovascular disease in society and increased prescribing rate of Beta blockers, adverse drug reaction monitoring is need of the time.

According to WHO, Pharmacovigilance is, "The science relating of detection, assessment, understanding and prevention of adverse effects or any other possible drug related problems". ${ }^{4}$ 
According to WHO, Adverse Drug Reaction (ADR) is, "A response to a drug that is noxious and unintended and occurs at doses normally used in human for the prophylaxis, diagnosis and treatment of disease, or for modification of physiological function". 6

Beta blockers have added new dimensions not only in the treatment of cardiovascular diseases but also in other conditions like prophylaxis of migraine, anxiety, essential tremors, glaucoma etc. ${ }^{7}$

While the benefits of Beta blockers are important in reducing mortality and morbidity of CVDs and other conditions, bradycardia, bronchospasm, exacerbation of variant (vasospastic) angina are known ADRs, sometimes requiring termination of their use.

The aim of our present study was to evaluate incidence, patterns and severity of beta adrenergic receptor antagonists induced adverse drug reactions in patients coming to the Department of Medicine at C.U. Shah Medical College, Surendranagar - Gujarat.

\section{METHODS}

The study protocol was approved by Institutional Ethics Committee (human). The present study was an open, noncomparative observational study to monitor ADRs associated with ACE inhibitors. The study was conducted between November 2011 to February 2013 at Department of Medicine on daily basis. Total 500 patients, irrespective of age and sex, coming to Department of Medicine, and taking beta blockers were enrolled in the study by taking an informed consent from each of them. All mentally compromised or unconscious patients and patients unable to respond to verbal questions were excluded from the study.

Reporting of all ACE inhibitors induced ADRs was done by filling CDSCO Adverse Drug Reaction Form. ${ }^{8}$ All ADR reports were evaluated according to 'WHO-UMC Causality Assessment Scale'.

\section{RESULTS}

Table 1: Gender wise distribution of patients with ADRs.

\begin{tabular}{|lll|}
\hline Sex & No. of people & $\%$ \\
\hline Male & 40 & 62.50 \\
\hline Female & 24 & 37.50 \\
\hline Total & 64 & 100 \\
\hline
\end{tabular}

A total of 64 ADRs (40 males and 24 females) were observed in 500 patients taking beta blockers with mean age of $57.41 \pm 9.56$.

A higher $\%$ of ADRs occurred in males $40(62.50 \%)$ than females $24(37.50 \%)$ shown in Table 1.
Table 2: Age wise distribution of patients with ADRs.

\begin{tabular}{|ll|}
\hline Age & $\%$ \\
\hline $\mathbf{3 1 - 4 0}$ & 6.25 \\
\hline $\mathbf{4 1 - 5 0}$ & 21.88 \\
\hline $\mathbf{5 1 - 6 0}$ & 31.25 \\
\hline $\mathbf{6 1 - 7 0}$ & 25.00 \\
\hline $\mathbf{7 0}$ & 15.62 \\
\hline
\end{tabular}

As displayed in Table 2, out of total 64 patients, 20 (31.25\%) were between 51-60 years of age group, 16 (25\%) were between 61-70 years of age group, 14 $(21.88 \%)$ were between $41-50$ years of age group, 10 (15.62\%) were more than 70 years and only 4 (6.25\%) were between $31-40$ years of age group.

Table 3: Distribution of ADRs by its type of reaction.

\begin{tabular}{|lll|}
\hline $\begin{array}{l}\text { Type of } \\
\text { ADR }\end{array}$ & ADR & \\
\hline A & N & \% \\
\hline B & 48 & 75 \\
\hline Total & 16 & 25 \\
\hline
\end{tabular}

Table 3 displays out of 64 ADRs, majority (75\%) of ADR were Type A reactions and only $25 \%$ ADRs were Type B reactions.

Table 4: Distribution of ADRs according to its severity.

\begin{tabular}{|lll|}
\hline Severity & ADR & \\
\hline Mild & N & \% \\
\hline Moderate & 20 & 31.25 \\
\hline Severe & 10 & 53.13 \\
\hline Total & $\mathbf{6 4}$ & 15.62 \\
\hline
\end{tabular}

As shown in Table 4, out of 64 ADRs $20(31.25 \%)$ were mild, $34(53.13 \%)$ were moderate, and $10(15.62 \%)$ were classified as severe in nature.

Table 5: Distribution of ADRs according to WHOUMC causality scale.

\begin{tabular}{|lll|}
\hline \multirow{2}{*}{ Classification } & ADR & \\
& $\mathbf{N}$ & $\mathbf{\%}$ \\
\hline Certain & 8 & 12.50 \\
\hline Probable/likely & 26 & 40.62 \\
\hline Possible & 22 & 34.38 \\
\hline Unlikely & 04 & 6.25 \\
\hline $\begin{array}{l}\text { Conditional } \\
\text { (Unclassified) }\end{array}$ & 04 & 6.25 \\
\hline $\begin{array}{l}\text { Un-assessable } \\
\text { (Unclassifiable) }\end{array}$ & 00 & 00 \\
\hline Total & $\mathbf{6 4}$ & $\mathbf{1 0 0}$ \\
\hline
\end{tabular}


Table 5 shows that, on the causality scale of WHO-UMC, maximum $26(40.62 \%)$ ADRs were classified as Probable, followed by $22(34.38 \%)$ ADRs were in Possible category, $8(12.5 \%)$ were in certain category, 4 (6.25\%) ADRs were unlikely and 4 (6.25\%) ADRs were Conditional.

Table 6: Distribution of ADRs with individual drugs.

\begin{tabular}{|lll|}
\hline $\begin{array}{l}\text { ADRs/Number of } \\
\text { ADRs }\end{array}$ & Drug & N \\
\hline Bronchospasm/22 & Atenolol & 10 \\
\cline { 2 - 3 } & Metoprolol & 8 \\
\cline { 2 - 3 } & Propranolol & 4 \\
\hline Bradycardia/10 & Atenolol & 8 \\
\cline { 2 - 3 } & Metoprolol & 2 \\
\hline Fatigue/8 & Atenolol & 2 \\
\cline { 2 - 3 } & Metoprolol & 4 \\
\cline { 2 - 3 } & Nebivolol & 2 \\
\hline Nausea/G.I.Upset/8 & Atenolol & 2 \\
\cline { 2 - 3 } & Metoprolol & 4 \\
\cline { 2 - 3 } & Nebivolol & 2 \\
\hline Erectile dysfunction/4 & Atenolol & 4 \\
\hline Dry cough/4 & Atenolol & 4 \\
\hline Altered lipid profile/2 & Atenolol & 2 \\
\hline Insomnia/2 & Metoprolol & 2 \\
\hline Night mares/2 & Metoprolol & 2 \\
\hline Diarrhoea/2 & Atenolol & 2 \\
\hline Total & \\
\hline
\end{tabular}

Out of total 64 ADRs, maximum $(n=22)$ cases were of bronchospasm. Out of that, maximum cases $(n=10)$ were because of Atenolol. Out of total 22 cases of same, 2 cases were severe.

Bradycardia was recorded in 10 patients. All the 10 cases were severe and required hospitalization. Here also cases of atenolol induced bradycardia were maximum.

Fatigue was reported by 8 cases, Nausea/GI upset was reported in 8 patients taking beta blockers, erectile dysfunction was reported by 4 patients, Dry cough was reported by 4 patients.

Only two patients were identified, who had altered lipid profile by beta blockers. In WHO-UMC scale, both were categorized into possible category.

Moreover, out of 64 cases, comparatively rare ADRs like Insomnia, Nightmares and Diarrhoea were also reported.

\section{DISCUSSION}

In our study, male population taking beta blockers are more prone to ADRs than females. According to recent survey overall tolerability of anti-hypertensive medicines is likely to be similar in men and women. ${ }^{10-12}$
In this study, out of 64 ADRs, 24(75\%) ADRs were type A reactions e.g. Bronchospasm. So, they can be prevented if given after taking proper history. Also in a literature review conducted on ten studies published between 1994 to 2001, cardiovascular drug induced ADRs were preventable in $17.9 \%$ cases. $^{13}$

While classifying ADRs according to severity of reaction, most of ADRs $(n=34)$ were moderate and required change or stoppage of drug. Out of 64 cases, 10 cases were severe in nature e.g. bradycardia, bronchospasm etc. According to another similar study conducted in an Indian hospital, 35\% ADRs were mild, 58.83\% were moderate and $6.66 \%$ ADRs were severe in nature. ${ }^{14}$

On causality assessment by WHO-UMC scale, out of 64 cases, $48(75 \%)$ cases were classified into Probable and Possible category.

As shown in table 6, bronchospasm $(n=22)$ was the most common ADR by beta blockers, while in other study carried out at South Delhi, common ADRs by beta blockers were giddiness, bronchospasm, headache, bradycardia, impotence etc. ${ }^{15}$ During present study, it was observed that many smokers and patients with the history of COPD and Bronchial asthma were prescribed with beta blockers. So it seems that proper history taking should be given more importance.

Fatigue was reported by 8 patients only, as literature suggest that incidence of fatigue is higher but in present study, it was comparatively lesser, this might be because, patients usually don't report fatigue as ADR to treating doctor. $^{16}$

Dry cough is rare side effect by beta blockers but we noted 4 cases of the same.

As shown in table 6, majority of ADRs by beta blockers were because of Atenolol, it might be because Atenolol is most frequently prescribed beta blocker. ${ }^{15}$

\section{CONCLUSION}

From results and discussion of this study we conclude that incidence of ADRs by Beta adrenoreceptor antagonists is $12.80 \% \%$ with Bronchospasm as most common ADR followed by Bradycardia. Only few ADRs due to Beta blockers are severe in nature otherwise most are mild to moderate. As Atenolol is most frequently used Beta blocker, ADRs due to Atenolol are more common. Many ADRs can be prevented by giving emphasis on taking proper history of patient before prescribing the same.

\section{ACKNOWLEDGEMENT}

We are thankful to Dean, Dr H. H. Agravat sir for allowing us to carry out this research project in our hospital. Authors would like to thanks to whole 
Department of Pharmacology and Medicine for their help to accomplish this study.

Funding: No funding sources

Conflict of interest: None declared

Ethical approval: The study was approved by the Institutional Ethics Committee (Human)

\section{REFERENCES}

1. Bonow RO, Smaha LA, Smith SC Jr, Mensah GA, Lenfant C. World Heart Day 2002: the international burden of cardiovascular disease: responding to the emerging global epidemic. Lenfant C Circulation. 2002;106(13):1602-5.

2. LaPointe NM, Jollis JG. Medication errors in hospitalized cardiovascular patients. Arch Intern Med. 2003;163(12):1461-6.

3. Jose J, Rao GM. Pattern of adverse drug reactions notified by spontaneous reporting in an Indian tertiary care teaching hospital. Pharmacol Res. 2006;226-33.

4. Prakash S. Pharmacovigilance in India. Indian $\mathbf{J}$ Pharmacol. 2007;39:123.

5. WHO. The importance of pharmacovigilance, safety monitoring of medical products. WHO Geneva, 2002.

6. Edward IR, Aronson JK. Adverse drug reactions: Definitions, diagnosis, and management. Lancet. 2000;356:12550-9.

7. Tripathi KD, Antiadrenergic drugs and drugs for glaucoma. Essentials of Medical Pharmacology, 6th ed. New Delhi: Jaypee Brothers. 2009:140-57.

8. Central drug standard control organization. Pharmacovigilance Programme of India; 2011 [Cited in
2011] Available from internet: http://cdsco.nic.in/ADR_form_PvPI.pdf.

9. The Uppsala monitoring centre. The use of WHO-UMC system for standardized case causality assessment; 2011 [Cited in 2011]. Available from internet: http://whoumc.org/Graphics/24734.pdf.

10. Jose J, Rao GM. Pattern of adverse drug reactions notified by spontaneous reporting in an Indian tertiary care teaching hospital. Pharmacol Res. 2006;226-33.

11. Lewis CE, Grandits GA, Flack J, McDonals R, Elmer PJ. Efficacy and tolerance of anti-hypertensive treatment to men and women with stage-1 diastolic hypertension: Result of the treatment of mild hypertension study. Arch Intern Med. 1996;156:377-85.

12. Montastruc JL, Lapeyre-Mestre M, Bagheri H, Fooladi A. Gender differences in adverse drug reactions: Analysis of spontaneous reports to a regional pharmacovigilance center in France. Fundam Clinical Pharmacol. 2002;16:343-6.

13. Kanjanarat P1, Winterstein AG, Johns TE, Hatton RC, Gonzalez-Rothi R, Segal R. Nature of preventable adverse drug events in hospitals: a literature review. Am J Health Syst Pharm. 2003;60(17):1750-9.

14. Palanisamy S, Kottur SG, Rajasekaran A. A study on assessment, monitoring and reporting of adverse drug reaction in Indian hospital. Asian J Pharm Clin Res. 2011;4(3):112-6.

15. Hussain A, Aqil M, Alam MS, Khan MR, Kapur P, Pillai KK. A Pharmacovigilance Study of Antihypertensive Medicines at a South Delhi Hospital. Indian J Pharm Sci. 2009;71(3):338-41.

16. A study of atenolol side effects[Internet] 2011 Oct12 Available from: http://www.ehealthme.com/q/atenololside-effects-drug-interactions.

Cite this article as: Trivedi M, Acharya T, Kotadiya F, Vekariya R, Mehta D. Pharmacovigilance study of beta adrenergic receptor antagonists in patients visiting department of medicine of a tertiary care hospital, Surendranagar, Gujarat, India. Int J Basic Clin Pharmacol 2016;5:2332-5. 